\title{
Analysis of a winter regional haze event and its formation mechanism in the North China Plain
}

\author{
X. J. Zhao, P. S. Zhao, J. Xu, W. Meng, W. W. Pu, F. Dong, D. He, and Q. F. Shi \\ Institute of Urban Meteorology, Chinese Meteorological Administration, Beijing 100089, China \\ Correspondence to: X. J. Zhao (xjzhao@ium.cn)
}

Received: 9 November 2012 - Published in Atmos. Chem. Phys. Discuss.: 9 January 2013

Revised: 29 April 2013 - Accepted: 2 May 2013 - Published: 13 June 2013

\begin{abstract}
A regional haze episode occurred in the Beijing, Tianjin and Hebei province (BTH) area in the North China Plain (NCP) from 16 to 19 January 2010. Data were collected and analyzed during the time frame of 14 through 23 January 2010 to include the haze event. The increase of secondary inorganic pollutants $\left(\mathrm{SO}_{4}^{2-}, \mathrm{NO}_{3}^{-}, \mathrm{NH}_{4}^{+}\right)$in $\mathrm{PM}_{2.5}$ was observed simultaneously at four sites, especially in the plain area of the BTH, which could be identified as a common characteristic of pollution haze in east China. The sulfate and nitrate in $\mathrm{PM}_{2.5}$ were mainly formed through the heterogeneous reaction process in the urban area. The organic matter (OM) increased more significantly at the Chengde (CD) site than the other three sites in the plain area. The secondary organic aerosols only existed during haze days at $\mathrm{CD}$ but in both haze and non-haze days at the other three sites, which suggested the greater regional impact of secondary formation process during the haze episode. The secondary formation of aerosol was one important formation mechanism of haze. The strong temperature inversion and descending air motions in the planetary boundary layer (PBL) allowed pollutants to accumulate in a shallow layer. The weak surface wind speed produced high pollutants concentration within source regions. The accumulation of pollutants was one main factor in the haze formation. The enhanced southwest wind in the last period of this episode transported pollutants to the downwind area and expanded the regional scope of the haze.
\end{abstract}

\section{Introduction}

China has undergone very rapid economic growth since the economic reforms began in 1978 and this has resulted in an increase in energy consumption, air pollution and asso- ciated health effects. In China large emissions were concentrated in the megacity clusters, such as BTH, the Pearl River delta (PRD) and the Yangtze River delta (YRD) regions (Parrish and Zhu, 2009). The BTH is one region in north China where the economic development is most active. It consists of two municipalities, Beijing and Tianjin, the capital city Shijiazhuang and other six cities of Hebei province. Chengde is one of the six cities and located in the northern mountainous area of Hebei.

With the rapid economic development, population expansion and urbanization, the BTH region has been experiencing a severe air pollution problem, especially aerosol pollution. The decrease of visibility is one of the most notable effects of aerosol. In the BTH region, the visibility showed a decreasing trend during 1980-2008 and haze days increased after the 1990s (Zhao et al., 2011a). In the urban area, haze days usually accompany severe air pollution. Numerous field studies provide abundant information about concentrations, compositions, source and optical properties of aerosol particles in major cities and other areas in the BTH. By comparing the different chemical characteristics of aerosols in dust, haze, and clear days in Beijing, Wang et al. (2005) pointed out that $\left(\mathrm{NH}_{4}\right)_{2} \mathrm{SO}_{4}, \mathrm{NH}_{4} \mathrm{NO}_{3}$, and $\mathrm{Ca}\left(\mathrm{NO}_{3}\right)_{2}$ were the major species on haze days in spring. Sun et al. (2006) investigated the chemical characteristics of $\mathrm{PM}_{2.5}$ and $\mathrm{PM}_{10}$ in haze-fog episodes in Beijing and found that the concentrations of elements and water-soluble ions in haze-fog episodes were more than 10 times higher than those on non-episode days. The serious air pollution in haze-fog episodes was strongly correlated with the meteorological conditions and the emissions of pollutants from anthropogenic sources. With analysis of the phase and mixing state of individual aerosol particles, Li et al. (2010) found that the agricultural biomass 


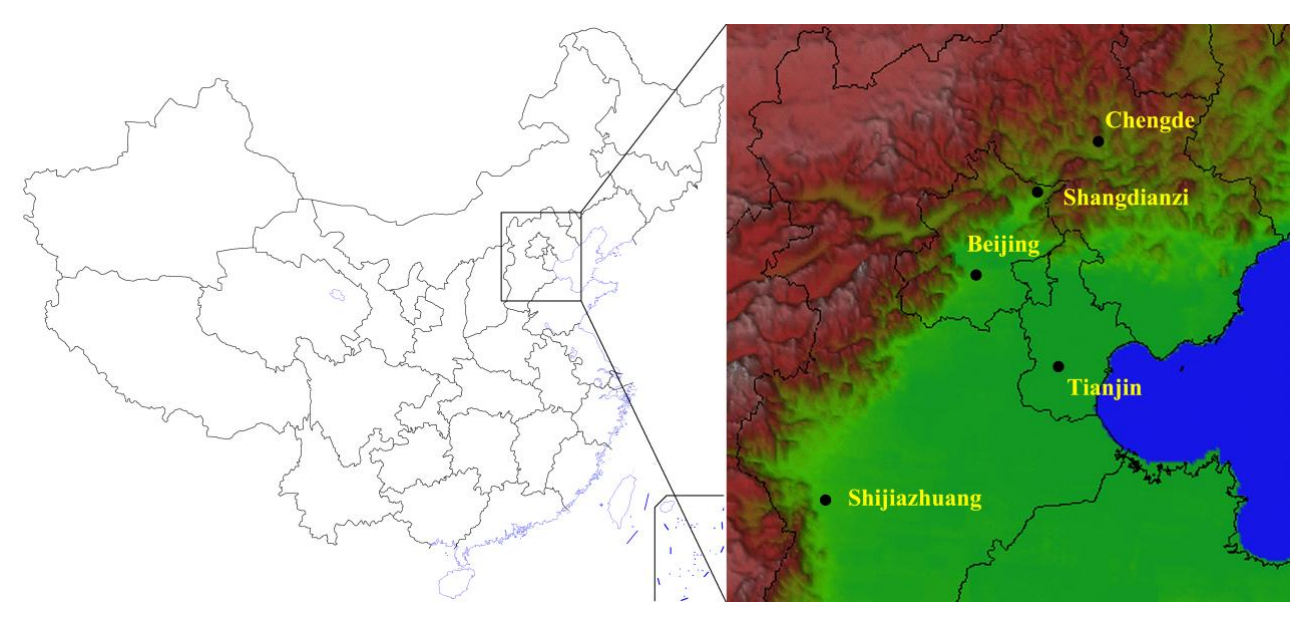

Fig. 1. Sampling sites of $\mathrm{PM}_{2.5}$

burning particles were significant contributors to the regional hazes in northern China and prominent in Beijing in June. During haze episodes, the aerosol scattering coefficient increased significantly and showed a different spatial distribution pattern under different meteorological conditions (Zhao et al., 2011b).

There are many similar studies in other cities and megacity clusters in China. Li et al. (2011) studied the mixing state of individual particles in Jinan city during a regional haze episode in winter. Their study confirmed that metal-catalyzed oxidation in the aqueous phase was a major pathway of sulfate formation. Huang et al. (2012) discussed the different chemical and optical properties of three haze types in Shanghai. The size distribution of aerosol in a long-lasting haze in Nanjing indicated that aerosol concentration in the diameter range of 0.6 to $1.4 \mu \mathrm{m}$ increased dramatically and mainly attributed to the remarkable increase of scattering coefficient and decrease of visibility (Kang et al., 2012). In Guangzhou, the particle mass-size distributions were bimodal and dominated by fine particles on haze days (Tan et al., 2009). These studies have provided abundant information about the formation of haze in different aspects. However, few studies have investigated the characteristics and formation of haze on a regional scale.

In this study, an intensive field experiment using various techniques was carried out at four sites in the BTH from 14 to 23 January 2010. The chemical and optical characteristics of the aerosol were analyzed, and the formation of haze from the point of chemical and meteorological process was investigated as well.

\section{Methods}

\subsection{Field observation}

\subsubsection{Sampling sites and collection}

As shown in Fig. 1, five sites were selected in the BTH region. Beijing and Tianjin are two municipalities surrounded by the Hebei province. Shijiazhuang is the capital of Hebei. Beijing, Tianjin, and most of Hebei are located in the NCP, which is bordered on the north by the Yanshan Mountains and on the west by the Taihang Mountains' edge of the Shanxi Plateau. Shangdianzi is a regional background station, which is $100 \mathrm{~km}$ northeast to the urban area of Beijing and located in the boundary of the plain area. It is also one of the Global Atmosphere Watch (GAW) stations. There are no densely populated and industrial areas within a distance of $30 \mathrm{~km}$ around the station, so the atmospheric pollution level at Shangdianzi station represents the background concentration of atmospheric pollutants in the economic developed regions of northern China. Due to the valley topography (Fig. 1), the prevailing winds at Shangdianzi are from the east-northeast and the west-southwest. Polluted air masses from urban areas and satellite towns of Beijing can therefore be easily transported to Shangdianzi by southwesterly winds, while relatively clean air masses arrive from other wind directions. A detailed introduction of the Shangdianzi site has been previously reported (Zhao et al., 2009; Lin, et al., 2008). Chengde is one city located in the northern mountainous area of Hebei, and outside the NCP region. Four sites were located within the urban areas of Beijing, Tianjin, Shijiazhuang and Chengde, and all monitoring was done on the roof of local meteorological bureaus. Another sampling site was set up in Shangdianzi. In this paper, the sampling sites for Shangdianzi, Beijing, Tianjin, Shijiazhuang and Chengde are abbreviated as SDZ, BJ, TJ, SJZ and CD. 
Aerosol samples of $\mathrm{PM}_{2.5}$ were collected on $90 \mathrm{~mm}$ polypropylene membrane filters and quartz fiber filters using two parallel medium-volume samplers $\left(100 \mathrm{~L} \mathrm{~min}^{-1}\right)$ at each site. The duration of sampling was generally $24 \mathrm{~h}$ from 09:00 to 08:00 LT (local time) the following day. Polypropylene membrane filters were used for analysis of inorganic elements. Quartz fiber filters were used for carbon and watersoluble ion components, and preheated at $800^{\circ} \mathrm{C}$ for $3 \mathrm{~h}$ before using. All of the filters were weighed with an analytical balance (Mettler XS105DU, reading precision $0.01 \mathrm{mg}$ ). Before and after sampling, the filters were weighed after being equilibrated for $24 \mathrm{~h}$ in a desiccator. All the samples were stored in a refrigerator under $3{ }^{\circ} \mathrm{C}$ and analyzed for chemical species within one month. More detailed information about the quality control of sampling, weighting and analyzing of filters has been provided in another work (Zhao et al., 2013).

\subsubsection{Automatic $\mathrm{PM}_{2.5}$ and gases monitor}

The real-time mass concentrations of $\mathrm{PM}_{2.5}$ were measured by a tapered element oscillating microbalance (Thermo Electron Corporation, TEOM 1400a at BJ and SDZ and 1405D at $\mathrm{TJ})$. Concentrations of sulfur dioxide $\left(\mathrm{SO}_{2}\right)$, ozone $\left(\mathrm{O}_{3}\right)$ and its precursors $\left(\mathrm{CO}, \mathrm{NO}, \mathrm{NO}_{2}\right.$ and $\left.\mathrm{NO}_{\mathrm{x}}\right)$ at the $\mathrm{BJ}$ station were observed by a set of commercial instruments from Ecotech, Inc., Australia. The instruments include an EC9810 ozone analyzer, EC9830 CO analyzer, EC9841 $\mathrm{NO}_{\mathrm{x}}$ analyzer and $\mathrm{EC} 9850 \mathrm{SO}_{2}$ analyzer. The precision of these four analyzers is $1.0 \mathrm{ppb}, 0.1 \mathrm{ppm}, 0.5 \mathrm{ppb}$ and $0.5 \mathrm{ppb}$, respectively. At TJ and SDZ stations, gases were observed by a set of commercial instruments from Thermo Environmental Instrument, Inc., USA. The instruments include a TE49C $\mathrm{O}_{3}$ analyzer, TE48C CO analyzer, TE 42CTL $\mathrm{NO}_{\mathrm{x}}$ analyzer and a $\mathrm{TE} 43 \mathrm{C} \mathrm{SO}_{2}$ analyzer. The precision of these four analyzers is $1.0 \mathrm{ppb}, 0.1 \mathrm{ppm}, 0.4 \mathrm{ppb}$ and $1.0 \mathrm{ppb}$, respectively. All instruments at each site are housed in an air-conditioned room with a relatively constant temperature. The TEOM instrument is operated with a hydrophobic filter material to reduce the humidity of the incoming sampled air. The sample stream is preheated to $50^{\circ} \mathrm{C}$ before entering the mass transducer, and hence semi-volatiles such as ammonium nitrate and water are not measured. The filter loading percentage and flow rates of TEOM are checked once a week, and the filter is replaced when the filter loading percentage is greater than $30 \%$. The averaging time was set to $5 \mathrm{~min}$, and subsequently processed to hourly means in this study. The uncertainty in hourly measurement was $\pm 1.50 \mu \mathrm{g} \mathrm{m}^{-3}$. For gas measurement instruments, daily zero/span checks are automatically done using a dynamic gas calibrator (TE 146C) in combination with a zero air supply (TE111) and a set of standard reference gas mixtures (Chemical Metrology \& Analytical Science Division, National Institute of Metrology, Beijing, China). Multipoint calibrations are made every 3-6 months. For ozone, the standards are traceable to the Standard Reference Photometer (SRP) maintained by the WMO World Calibration Centre in Switzerland (EMPA). The national standard gases of $\mathrm{SO}_{2}$, $\mathrm{NO}$, and $\mathrm{CO}$ are compared against NIST (National Institute of Standards and Technology)-traceable standards from Scott Specialty Gases, USA. After the correction of data on the basis of multipoint calibration, hourly average data are calculated and are used for further analysis in this study.

\subsubsection{Optical observations}

At the regional background station SDZ, the aerosol scattering coefficient $\left(\sigma_{\mathrm{sp}}\right)$ was measured by an integrating nephelometer (Model M9003, EcoTech, Australia). The BC aerosol concentration was measured with an aethalometer (Model AE31, Magee Scientific, USA). The AE31 Aethalometer measured the optical attenuation of light from LED lamps with seven different wavelengths (370, 470, 520, $590,660,880$, and $950 \mathrm{~nm}$ ) transmitted through the aerosols deposited continuously on a quartz fiber filter. The attenuation of light is converted to the $\mathrm{BC}$ mass concentration using wavelength dependent calibration factors as recommended by the manufacturer. The light absorption coefficient $\left(\sigma_{\mathrm{ap}}\right)$ was indirectly calculated with the BC concentration by the method introduced below. The detailed working principle and maintenance of the instruments has been discussed previously (Zhao et al., 2011b; Yan et al., 2009). An aerosol lidar (ALS300, EZ manufactured by Leosphere) was employed in this field campaign at SDZ. The lidar system is based on $355 \mathrm{~nm} \mathrm{Nd:YAG} \mathrm{pulsed} \mathrm{laser} \mathrm{operating} \mathrm{at} 16 \mathrm{~mJ}$ with $20 \mathrm{~Hz}$ repetition rate. The backscattered light is collected by an optical system and its intensity is measured by a photo-detector. The amount of the collected optical radiation is converted into an electronics signal and stored onto a computer. The lidar continuously operated with $30 \mathrm{~min}$ intervals and $15 \mathrm{~m}$ height resolution. The maximum range is about $20 \mathrm{~km}$. The backscatter and extinction coefficient profiles are retrieved using the well known Klett-Fernald-Sasano evaluation approach with an assumption of so-called lidar ratio (Klett, 1981, 1985; Fernald, 1984). The aerosol optical depth integrated over the maximum of the available lidar range.

\subsection{Chemical analysis}

Each polypropylene and blank filter was cut into fragments and digested with $16 \mathrm{ml}$ concentrated $\mathrm{HNO}_{3}$ and $4 \mathrm{ml}$ concentrated $\mathrm{HClO}_{4}$ in a conical flask, and then heated until there was $\sim 3 \mathrm{ml}$ residual left. After cooling, the solution was filtered, and then diluted to $15 \mathrm{ml}$ with ultrapure water. A total of 19 elements (Al, As, Ba, Ca, Cd, Co, Cr, Cu, Fe, $\mathrm{K}, \mathrm{Mg}, \mathrm{Mn}, \mathrm{Ni}, \mathrm{P}, \mathrm{Pb}, \mathrm{Sr}, \mathrm{Ti}, \mathrm{V}$ and $\mathrm{Zn}$ ) were analyzed by inductively coupled plasma spectroscopy and atomic emission spectroscopy (ICP-AES)( (Model: ULTIMA, JOBIN-YVON Company, France).

One fourth of each quartz fiber filter was put into a glass tube and $10 \mathrm{ml}$ of deionized water was added. After a 15 min ultrasonic bath at room temperature, the solution was 

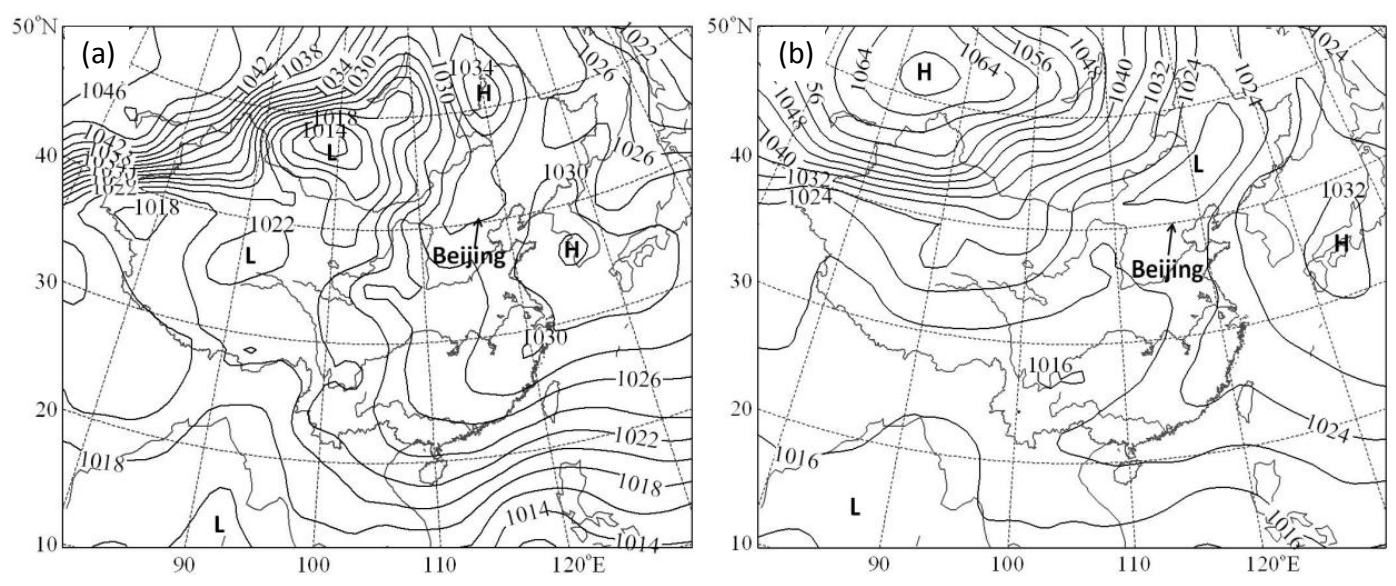

Fig. 2. Surface weather patterns at 08:00 (LT) on (a) 18 January 2010 and (b) 19 January 2010.

drawn into a $5 \mathrm{ml}$ syringe, filtered by a syringe filter, and injected into a polymeric vial with filter cap. The polymeric vials were put into a Dionex AS-DV Autosampler and analyzed by an ion chromatography (ICS-1000, DIONEX) for water-soluble ions $\left(\mathrm{Na}^{+}, \mathrm{NH}_{4}^{+}, \mathrm{K}^{+}, \mathrm{Mg}^{2+}, \mathrm{Ca}^{2+}, \mathrm{Cl}^{-}, \mathrm{NO}_{3}^{-}\right.$, and $\mathrm{SO}_{4}^{2-}$ ).

A $0.5 \mathrm{~cm}^{2}$ punch from each quartz-fiber filter was analyzed by a thermal optical carbon analyzer (DRI-2001A) for eight carbon fractions, following the IMPROVE_A protocol (Chow et al., 1993, 2001, 2007).

\subsection{Methods for aerosol absorption coefficient $\left(\sigma_{\mathrm{ap}}\right)$ calculation}

The aerosol light absorption coefficient $\left(\sigma_{\mathrm{ap}}\right)$ can be directly calculated from the attenuation measured by the Aethalometer or indirectly calculated based on the BC concentrations recorded by the instrument. The detailed calculation method has been described in Yan et al. (2008). In this work, the indirect method was employed to calculate the $\sigma_{\text {ap }}$ based on the following equation:

$\sigma_{\mathrm{ap}}=\alpha \times[\mathrm{BC}]$

where, $\alpha$ is the conversion factor or the $\mathrm{BC}$ absorption efficiency, and is adopted as $8.28 \mathrm{mg} \mathrm{m}^{-2}$ in this work to obtain the $\sigma_{\mathrm{ap}}$ at $532 \mathrm{~nm}$ with $\mathrm{BC}$ concentration at $880 \mathrm{~nm}$. This value had been used as the conversion factor in previous work at the SDZ station by Yan et al. (2009), which was obtained based on the result of the inter-comparison experiment conducted in southern China. Yan et al. (2009) had compared this value with those reported in previous studies. They found that it was within their variance of $\alpha$ for different regions and very close to the value of $8.0 \mathrm{mg} \mathrm{m}^{-2}$ obtained in the Beijing urban area (Bergin et al., 2001). This value of $\alpha$ is higher than the best estimate given by Bond and Bergstrom (2001) but still well within their variance of $\alpha$ for varying source regions.

\subsection{The meteorological data}

The meteorological data, mainly the visibility over China, was obtained from the China Meteorological Administration (CMA). The hourly meteorological data, wind direction, wind speed, relative humidity (RH), temperature and pressure were measured with an automatic weather station installed at the SDZ meteorological station. Wind parameters are observed at $10 \mathrm{~m}$ height, while temperature, pressure and moisture information are collected at $1.5 \mathrm{~m}$ height. Visibility was monitored with a forward scattering measuring visibility meter (Model FD 12, Vaisala Corporation, Finland) at SDZ. In the Beijing urban area, the wind profile with time resolution of $5 \mathrm{~min}$ was observed with a boundary layer wind profile lidar located at the Haidian meteorology station, approximately $4 \mathrm{~km}$ to the north of BJ site. The profile's range is $3500 \mathrm{~m}$ with $50 \mathrm{~m}$ vertical resolution. The radiosonde data of Beijing meteorological station (54511) was used to analyze the vertical structure of temperature in this work.

\section{Results and discussion}

\subsection{Meteorological condition and pollutant concentrations}

In winter, the NCP region is often dominated by cold highpressure system with low surface wind speeds, sometimes also accompanied by surface temperature inversion. Those conditions are favorable for the formation of haze or fog, and usually lead to high levels of pollutants concentration due to weak mixing and dispersion (Xu et al., 2011).

A surface weak high-pressure system persisted from 16 to 18 January 2010 in Beijing and the surrounding area and was replaced by a low-pressure system until 20 January. This weather condition was unfavorable for the dispersion of pollutants and resulted in the occurrence of a haze episode from 16 to 19 January. The weather system was finally terminated 

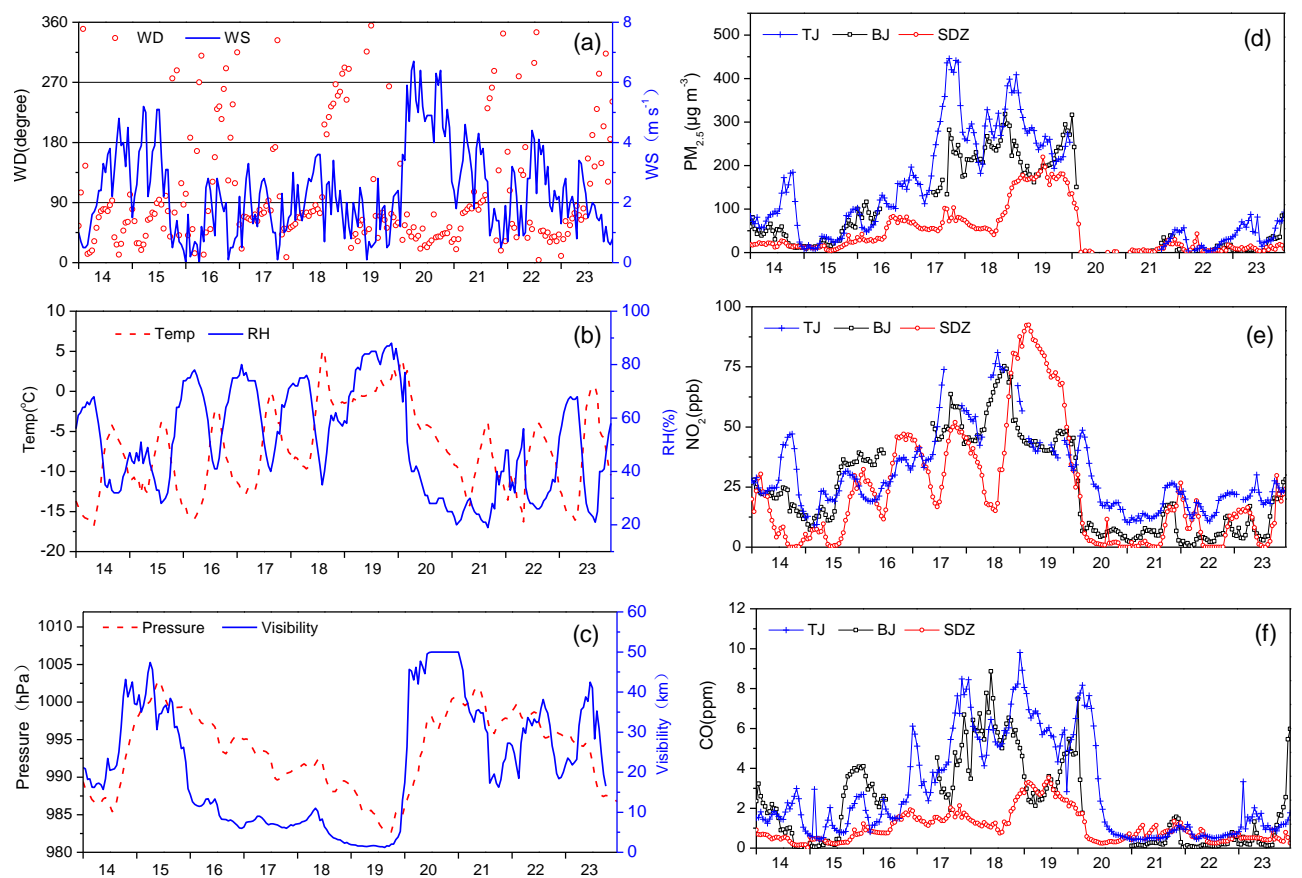

Fig. 3. Time series variations of meteorological parameters at SDZ and pollutants at TJ, BJ and SDZ from 14 to 23 January 2010 . (a) wind direction and wind speed $\left(\mathrm{m} \mathrm{s}^{-1}\right),(\mathbf{b})$ temperature $\left({ }^{\circ} \mathrm{C}\right)$ and relative humidity $(\%),(\mathbf{c})$ atmospheric pressure $(\mathrm{hPa})$ and visibility $(\mathrm{km}),(\mathbf{d})$ $\mathrm{PM}_{2.5}$ concentration $\left(\mu \mathrm{g} \mathrm{m}^{-3}\right)$, (e) $\mathrm{NO}_{2}(\mathrm{ppb})$, (f) $\mathrm{CO}(\mathrm{ppb})$.

by the Mongolia anticyclone with strong northerly wind on 20 January (Fig. 2). Under this synoptic condition, winds at the surface were very weak with the wind speed lower than $3.0 \mathrm{~m} \mathrm{~s}^{-1}$ at SDZ and even lower in the Beijing urban areas (lower than $2.0 \mathrm{~m} \mathrm{~s}^{-1}$ ). Both the temperature and relative humidity $(\mathrm{RH})$ showed evident diurnal variation. The temperature increased continuously day by day, and the RH remained high. The surface pressure persistently decreased during this episode (Fig. 3a-c). The weak winds and lower pressure were unfavorable for the dispersion of pollutants, which caused the accumulation of pollutants on a regional scale. As shown in Fig. 3, the particulate and gaseous pollutants (Fig. 3d-f) increased continuously from 16 to 18 January at three sites, while they decreased at $\mathrm{TJ}$ and $\mathrm{BJ}$, and increased obviously at SDZ on 19 January. The concentrations of $\mathrm{PM}_{2.5}$ and $\mathrm{CO}$ at $\mathrm{BJ}$ and $\mathrm{TJ}$ were evidently higher than that at SDZ. The highest concentration of $\mathrm{PM}_{2.5}$ was 445.6 and $318.1 \mu \mathrm{g} \mathrm{m}^{-3}$ at $\mathrm{TJ}$ and $\mathrm{BJ}$, respectively. The concentration of $\mathrm{CO}$ exceeded $8.0 \mathrm{ppm}$ at $\mathrm{TJ}$ and $\mathrm{BJ}$. The $\mathrm{NO}_{2}$ increased simultaneously at three sites and showed significant diurnal variation at SDZ. The average concentrations of $\mathrm{PM}_{2.5}, \mathrm{NO}_{2}$ and $\mathrm{CO}$ on haze days (16-19 January) were $5 \sim 8,2 \sim 6$ and $3 \sim 5$ times as high as that in non-haze days (all other days in the period from 14 through 23 January). The sharp increase of pollutants at SDZ on 19 January was mainly attributed to the regional transport, which will be discussed as a part of this study in the following section.

\subsection{Light extinction effect of aerosol in this episode}

Visibility as a standard meteorological parameter is regularly measured at synoptic meteorological stations all over the world. Since it is determined mostly by the light extinction by aerosol particles, this parameter can be considered as a good indicator of air pollution (Molnár et al., 2008). The standard visibility measurements are carried out under ambient relative humidity (RH), and strongly depend on the available atmospheric water vapor due to the hygroscopic growth of the particles. Consequently, the extinction effect of a given, dry aerosol volume concentration should be separated from that due to hygroscopic growth of the particles via adsorbed water vapor. The noon visibility data has been widely used to examine the spatiotemporal haze trends in the United States (Husar and Wilson, 1993; Schichte et al., 2001). Zhao et al. (2011c) pointed out that it was better to quantify haze days with the meteorological observation data at 14:00 (LT; visibility and RH) after comparison two methods of distinguishing haze days with daily mean and 14:00 (LT) meteorological data in the BTH area. Therefore, the visibility observed at 14:00 (LT) was employed in this study to reflect the aerosol extinction effect on a regional scale. The visibility data was obtained from the China Meteorological Administration (CMA). As shown in Fig. 4, the area with visibility lower than $10 \mathrm{~km}$ mostly appeared in the south of China on 16 January, and then gradually expanded northward and covered most regions of eastern China including Beijing 

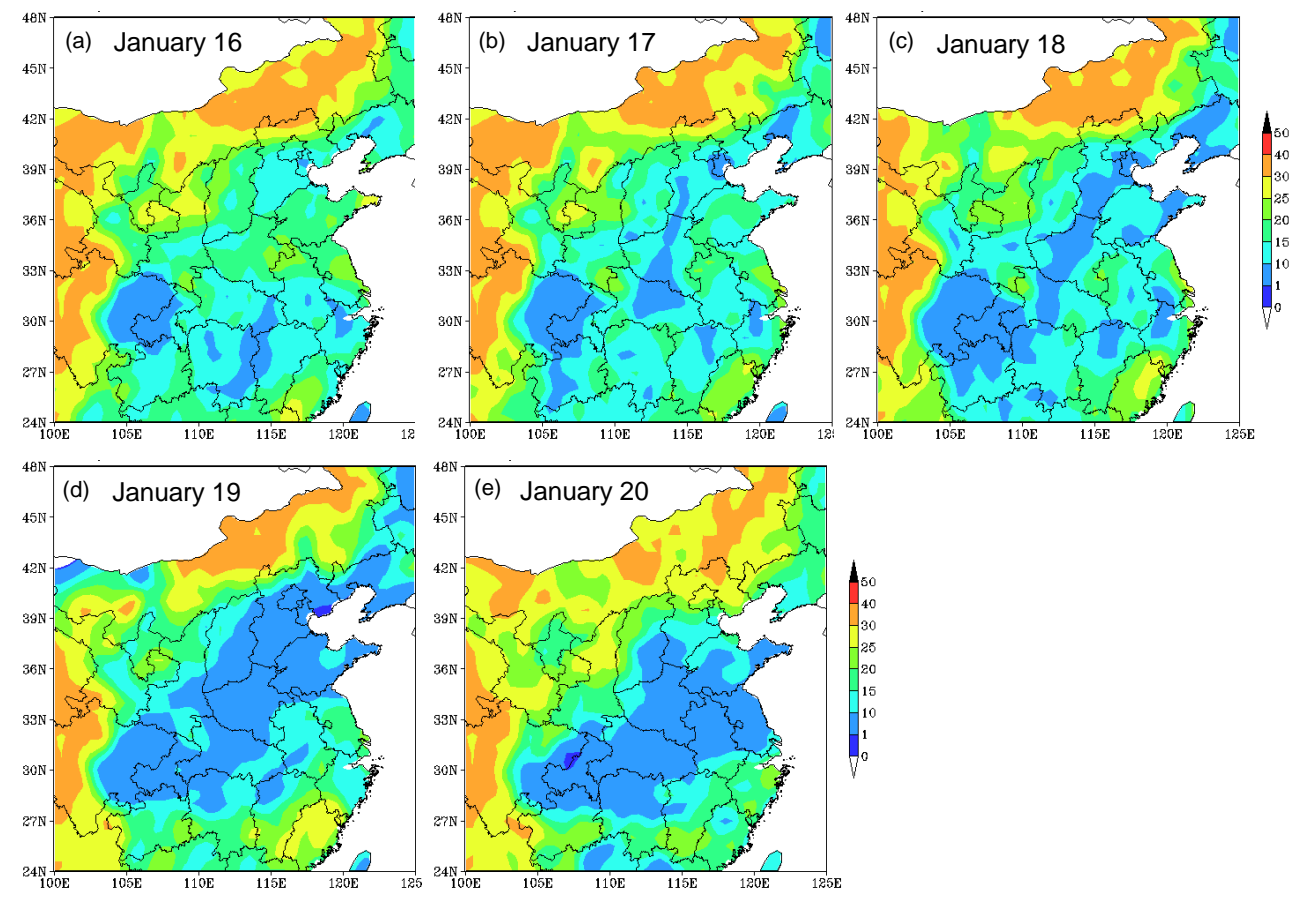

Fig. 4. Regional distribution of visibility (km) at 14:00 (LT) during 16-20 January.

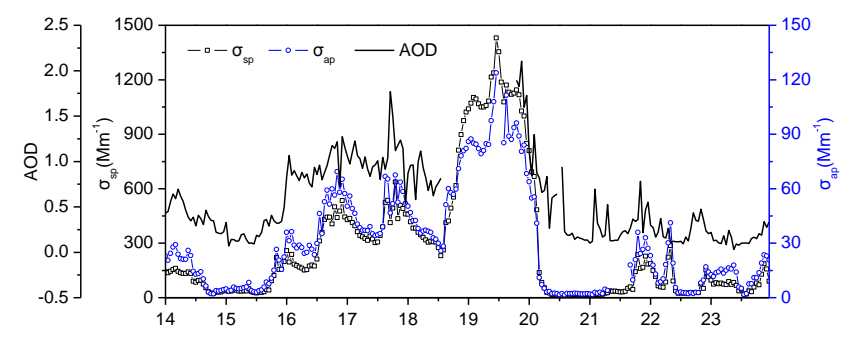

Fig. 5. Time series of aerosol scattering $\left(\sigma_{\mathrm{sp}}\right)$, absorption coefficient $\left(\sigma_{\text {ap }}\right)$ and aerosol optical depth (AOD) at SDZ from 14 to 23 January 2010 .

and Tianjin on 19 January, finally shifting to the south on 20 January driven by the strong northerly winds. Corresponding to the visibility variation, the weather phenomenon observed in the low visibility area was mainly haze at 14:00 (LT) from 16 to 18 January, mist was observed and began to increase on 19 January. The haze phenomenon recorded in daytime suggested that the aerosol loading was high enough in this episode to extinct the light and then cause low visibility. These hygroscopic aerosol particles accompanied with increased RH ultimately resulted in the lower visibility, especially during the nighttime.

The extinction by aerosol included scattering and absorption. The observed $\sigma_{\mathrm{sp}}$ and calculated $\sigma_{\mathrm{ap}}$ at SDZ are presented in Fig. 5. The AOD retrieved with the lidar observation is presented as well, which can provide columnar aerosol properties. Similar to the $\mathrm{PM}_{2.5}$ concentration, the $\sigma_{\mathrm{sp}}$ and $\sigma_{\mathrm{ap}}$ gradually increased from 16 January to midday on 18 January, and showed significant diurnal variation with high values around evening and low values around noon. The AOD began to increase on 16 January and gradually increased in the following two days. There was no obvious diurnal variation observed in AOD. All the three parameters increased significantly in the afternoon of 18 January and reached their maxima on 19 January with values of $1430.1 \mathrm{~km}^{-1}, 219.4 \mathrm{~km}^{-1}$ and 2.1 for $\sigma_{\mathrm{sp}}, \sigma_{\mathrm{ap}}$ and AOD, respectively. In this period, the lidar captured several high values of AOD (above 1.5) in the end of the haze episode, though the values of AOD were mostly missed on 19 January due to the presence of cumulus clouds at the top of the PBL. The annual average AOD at $550 \mathrm{~nm}$ of Beijing was 0.8 derived from the MODIS (Moderate Resolution Imaging Spectroradiometer) dataset (Xu et al., 2011). The enhanced AOD indicated that the aerosol loading in the vertical direction was also increased significantly on 19 January. On haze days (16-19 January), the average values of $\sigma_{\mathrm{sp}}$ and $\sigma_{\mathrm{ap}}$ were 577.3 and $55.6 \mathrm{Mm}^{-1}$, and were 8.1 and 5.2 times as high as that in non-haze days, respectively. Compared with the seasonal averages of $\sigma_{\mathrm{sp}}$ in winter, $176 \mathrm{~km}^{-1}$ observed at SDZ in 2008, the $\sigma_{\mathrm{sp}}$ averagely increased 2.3 times on haze days (Zhao et al., 2011b). However, the mean $\sigma_{\mathrm{sp}}$ and $\sigma_{\mathrm{ap}}$ were lower than that observed at Wuqing (a site located between $\mathrm{BJ}$ and $\mathrm{TJ}$ ) with values of 742 and $112 \mathrm{Mm}^{-1}$ during the pollution episode in spring and 874 and $85 \mathrm{Mm}^{-1}$ in summer, respectively (Ma et al., 2011). The daily average $\sigma_{\text {sp }}$ and $\sigma_{\text {ap }}$ was 1116.7 and $89.4 \mathrm{Mm}^{-1}$ on 19 January, which caused 

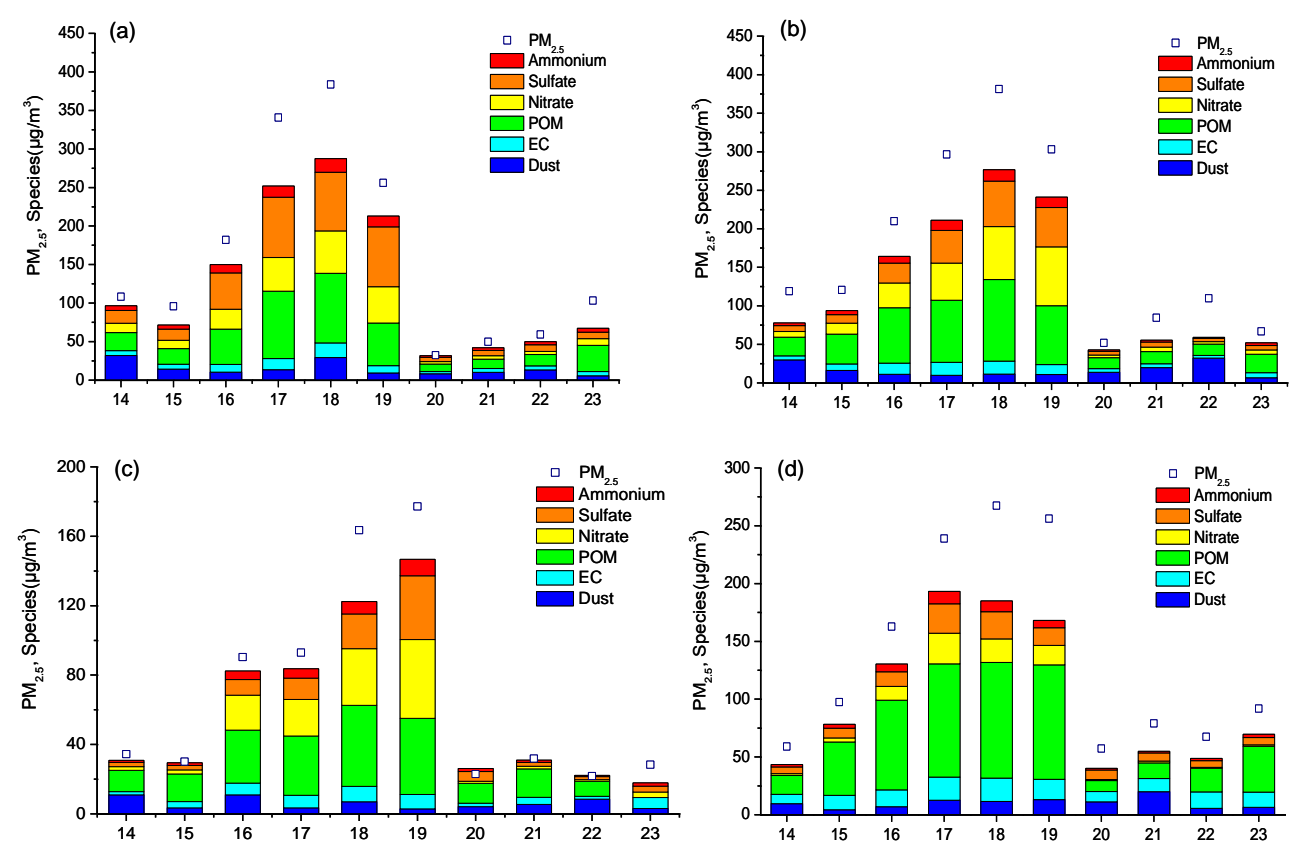

Fig. 6. Variation of concentrations of $\mathrm{PM}_{2.5}$ and chemical species at (a) TJ, (b) BJ, (c) SDZ and (d) CD from 14 to 23 January 2010.

further reduction of visibility. The visibility on this day was mostly lower than $2 \mathrm{~km}$. The rapid increase of aerosol loading at the surface and in the vertical distribution was mostly attributed to the regional transport, which is demonstrated in detail later in this paper.

\subsection{Chemical characteristics and secondary formation of this episode}

The results of chemical analysis of $\mathrm{PM}_{2.5}$ at four sites in Beijing, Tianjin and the Hebei province are presented in this section to identify the chemical characteristics of the aerosol during this haze episode (16-19 January) and discuss secondary formation. The sampling of $\mathrm{PM}_{2.5}$ was missed at SJZ during this episode and not analyzed in this paper. The dust matter in $\mathrm{PM}_{2.5}$ was calculated as the sum of oxides of aluminum, calcium, iron, titanium, magnesium and silicon (i.e., mineral dust $=1.89 \mathrm{Al}+2.14 \mathrm{Si}+1.4 \mathrm{Ca}+1.43 \mathrm{Fe}+$ $1.66 \mathrm{Mg}+1.67 \mathrm{Ti}$ ) based on our measurement of the concentration of these elementals (Taylor and Mclennan, 1985; Hueglin et al., 2005). The concentration of Si was estimated according to the average ratio of $\mathrm{Si} / \mathrm{Al}$ (3.9) obtained from Zhang et al. (2003). Organic material (OM) was obtained by multiplying OC concentrations by a factor of 1.2 , accounting for hydrogen and oxygen in the organic compounds. This conversion factor had been used in previous work in Beijing (Sun et al., 2004). The $\mathrm{PM}_{2.5}$ concentrations were obtained from a gravimetric analysis with quartz fiber filters, due to their better collection efficiency (Zhao et al., 2013). The results showed that the $\mathrm{PM}_{2.5}$ concentration increased sharply during the haze episode. The $\mathrm{SO}_{4}^{2-}, \mathrm{NO}_{3}^{-}, \mathrm{NH}_{4}^{+}$,
OM, dust matter, and element carbon were the six dominant species in $\mathrm{PM}_{2.5}$ at fours sites in both haze and non-haze days (Fig. 6). However, the secondary inorganic pollutants $\left(\mathrm{SO}_{4}^{2-}\right.$, $\mathrm{NO}_{3}^{-}$and $\mathrm{NH}_{4}^{+}$) and $\mathrm{OM}$ increased evidently during the haze episode and became the dominant components of $\mathrm{PM}_{2.5}$. The total concentrations of $\mathrm{SO}_{4}^{2-}, \mathrm{NO}_{3}^{-}$and $\mathrm{NH}_{4}^{+}$exhibited the highest levels during this episode with the average value of 127.0, 113.5, 56.9 and $46.2 \mu \mathrm{g} \mathrm{m}^{-3}$ at TJ, BJ, SDZ and CD, respectively. The three components together accounted for 44.8, 37.7, 41.9 and $20.1 \%$ of $\mathrm{PM}_{2.5}$ mass concentration at TJ, BJ, SDZ and CD, respectively. The concentration of those components on haze days was about $4.3 \sim 9.1$ times higher than that on non-haze days at these four sites, and was significantly higher in large cities, Beijing and Tianjin, than in the regional background area (SDZ) and in the city to the north of Hebei province (CD) on haze days. However, the percentages were comparable at three sites in the North China Plain, and considerably higher than that at the $\mathrm{CD}$ site. The increase of secondary inorganic pollutants had been observed in the pollution haze in several cities in eastern China (Sun et al., 2006; Wang et al., 2006; Tan et al., 2009; Li et al., 2011; Huang et al., 2012 ). This phenomenon was observed simultaneously at four sites on a regional scale in this study, which could be identified as a common characteristic of pollution haze in eastern China.

The higher contribution of sulfate and nitrate in a haze episode could be related to high oxidation rates of $\mathrm{SO}_{2}$ and $\mathrm{NO}_{2}$. Previous studies have indicated that the sulfur oxidation ratio $\mathrm{SOR}=\mathrm{nSO}_{4}^{2-} /\left(\mathrm{nSO}_{4}^{2-}+\mathrm{nSO}_{2}\right)(\mathrm{n}$ refers to molar concentration) and nitrogen oxidation ratio $\mathrm{NOR}=$ $\mathrm{nNO}_{3}^{-} /\left(\mathrm{nNO}_{3}^{-}+\mathrm{nNO}_{2}\right)$ can be used to estimate the degree 
Table 1. SOR, NOR and OC/EC during haze days and non-haze days at four sites.

\begin{tabular}{lccccccccccccc}
\hline & \multicolumn{3}{c}{ TJ } & \multicolumn{3}{c}{ BJ } & \multicolumn{3}{c}{ SDZ } & \multicolumn{3}{c}{ CD } \\
\cline { 2 - 6 } & SOR & NOR & OC/EC & SOR & NOR & OC/EC & SOR & NOR & OC/EC & SOR & NOR & OC/EC \\
HD & 0.16 & 0.40 & 4.40 & 0.29 & 0.51 & 4.53 & 0.16 & 0.33 & 4.09 & N & N & 4.34 \\
NHD & 0.06 & 0.19 & 3.00 & 0.16 & 0.28 & 3.27 & 0.23 & 0.20 & 4.47 & N & N & 1.72 \\
Ratio & 2.50 & 2.14 & 1.47 & 1.81 & 1.78 & 1.39 & 0.69 & 1.67 & 0.91 & N & N & 2.52 \\
\hline
\end{tabular}

HD: haze days; ND: normal days; ratio: the ratio of values in HD to that in ND; N: no data.
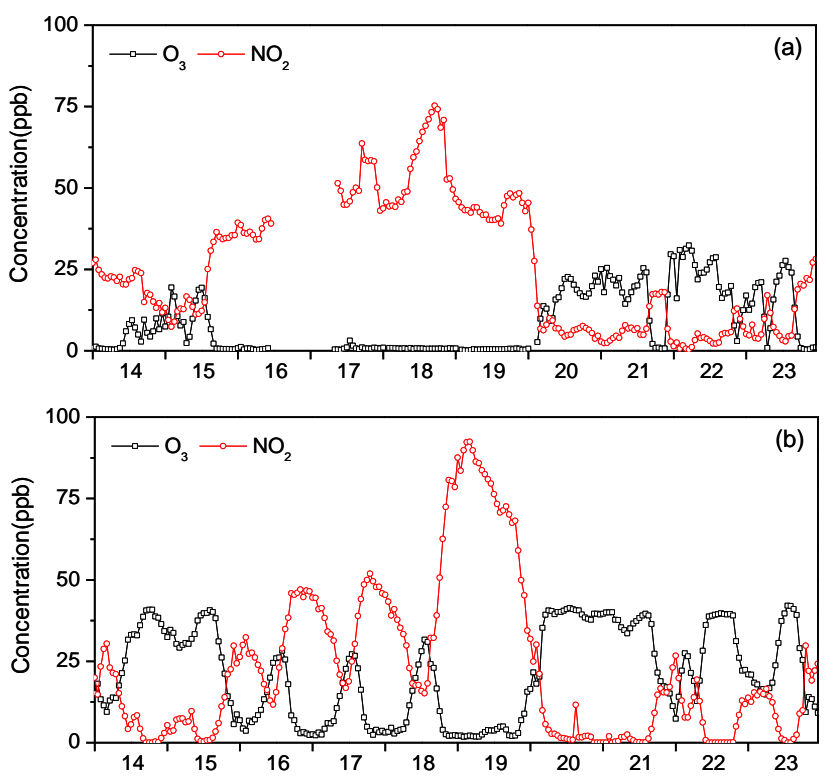

Fig. 7. Time series variations of $\mathrm{O}_{3}$ and $\mathrm{NO}_{2}$ at (a) $\mathrm{BJ}$ and (b) $\mathrm{SDZ}$ from 14 to 23 January 2010.

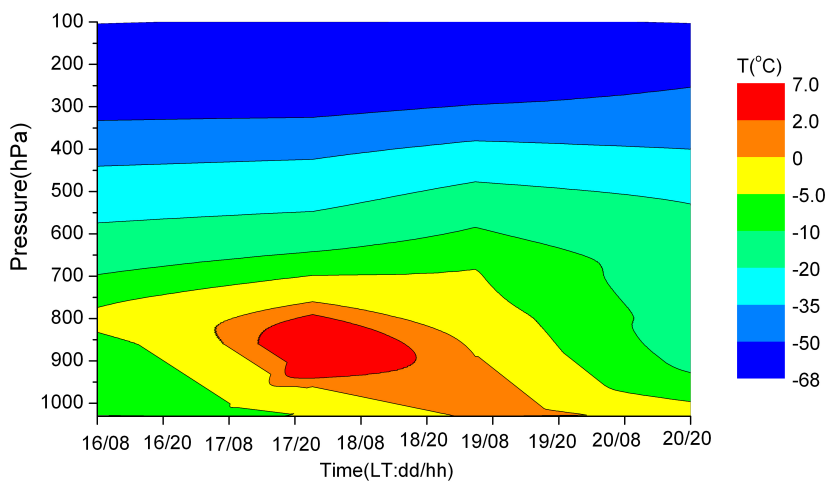

Fig. 8. Variation of temperature in vertical direction from 16 to 20 January.

of secondary formation of nitrogen and sulfur (Sun et al., 2006; Wang et al., 2006). As shown in Table 1, the average values of SOR and NOR were 0.16 and 0.40 on haze days at $\mathrm{TJ}$ and about 1.50 and 1.14 times higher than that on nonhaze days, respectively. At BJ, both SOR and NOR on haze days with values of 0.29 and 0.51 were about 1.8 times as much as that in the non-haze days. The increased SOR and NOR on haze days indicated the effect of secondary formation. The conversion of $\mathrm{SO}_{2}$ to sulfate was mainly attributed to the gas-phase oxidation by $\mathrm{OH}$ and $\mathrm{H}_{2} \mathrm{O}_{2}$ radical or heterogeneous oxidation (Seinfeld et al., 1986; Calvert et al., 1985). Many studies suggested that the conversion of $\mathrm{SO}_{2}$ to sulfate in winter haze was more significant through the aqueous phase oxidation of $\mathrm{SO}_{2}$ by the catalysis of the transition metals instead of the gas-phase oxidation (Sun et al., 2006; Tan et al., 2009; Li et al., 2011; Sun et al., 2013). Our measurements confirmed this view in our study area. As shown in Fig. 7a, the concentration of $\mathrm{NO}_{2}$ was very high but the $\mathrm{O}_{3}$ concentration was less than $5 \mathrm{ppb}$ during the haze episode (16 to 19 January) at BJ (TJ was similar to BJ and not shown here); both of them had no evident diurnal variation. These results suggested that the photochemical activity was very weak during the haze period. The high levels of $\mathrm{NO}_{2}$ and the weak photochemical activity could not produce sufficient conversion oxidants $\left(\mathrm{OH}\right.$ and $\mathrm{H}_{2} \mathrm{O}_{2}$ radicals) for gas-phase oxidation of $\mathrm{SO}_{2}$ (Poppe et al., 1993; Hua et al., 2008). The increased relative humidity on haze days (Fig. 3) was a favorable factor for the aqueous phase oxidation of $\mathrm{SO}_{2}$. The formation of nitrate in the urban area was probably through the heterogeneous hydrolysis process. By analysis of sulfate, nitrate, and ammonium in $\mathrm{PM}_{2.5}$ in four cities in China, Pathak et al. (2009) pointed out that the nitrate was most probably formed via the heterogeneous hydrolysis of $\mathrm{N}_{2} \mathrm{O}_{5}$ on the surface of the moist and acidic aerosols in Beijing and Shanghai, especially during humid and hazy weather. The formation of nitrate in $\mathrm{PM}_{2.5}$ is still less well understood and needs further study in the future. However, the observed results were different at SDZ than from those at two urban sites. The NOR was higher on haze days with a value of 0.33 , while the SOR on haze days at 0.16 was lower than 0.23 on non-haze days. In Fig. 7b, it could be found that the $\mathrm{NO}_{2}$ and $\mathrm{O}_{3}$ showed obvious diurnal variations with a reserved trend from 16 to 18 January. The concentration of $\mathrm{O}_{3}$ was highest around noon and lowest in the night, which was the typical characteristic of photochemical process. On the last day of the haze, namely 19 January, the variations of $\mathrm{NO}_{2}$ and $\mathrm{O}_{3}$ were similar to that at $\mathrm{BJ}$, and the SOR and NOR arrived at their maxima, which probably suggested the role of a heterogeneous reaction process. At the same time, the concentrations of $\mathrm{SO}_{4}^{2-}$ and $\mathrm{NO}_{3}^{-}$increased to their highest levels of this 

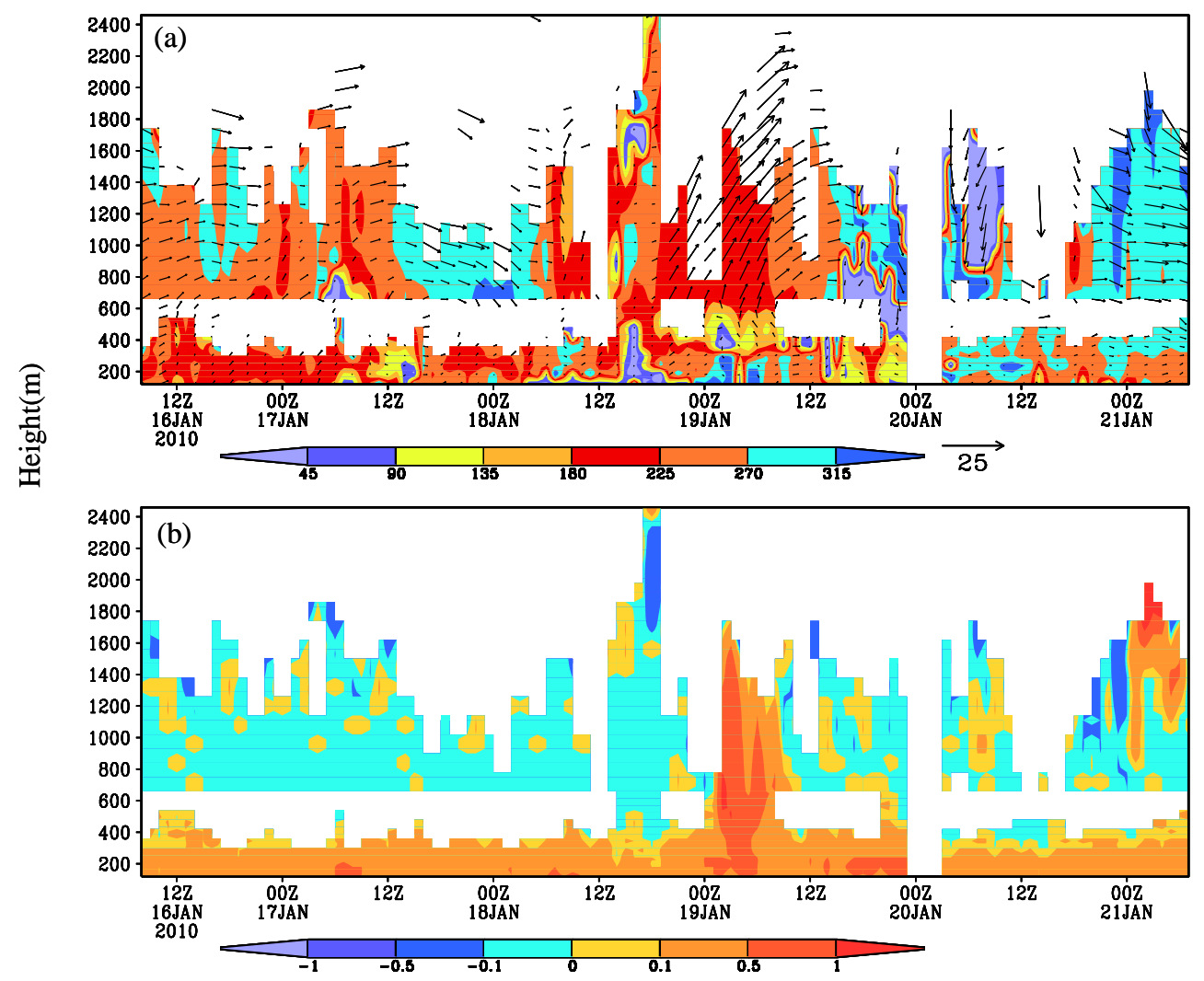

Fig. 9. The lidar measurement of wind profile in the Beijing region from 16 to 21 January. (a) horizontal wind vectors and wind direction (shaded); (b) vertical winds $\left(\mathrm{m} \mathrm{s}^{-1}\right)$.

study period (Fig. 6c), which accompanied with the sharply increase of $\mathrm{NO}_{2}$ and other pollutants $\left(\mathrm{PM}_{2.5}\right.$ and $\left.\mathrm{CO}\right)$ indicated the impact of regional transport (Fig. 3d-f). The regional transport of pollutants will be discussed in the next section. The lower SOR might be attributed to the sharp decrease of $\mathrm{SO}_{2}$ relative to the decrease of $\mathrm{SO}_{4}^{2-}$ diluted by the strong northerly wind. The SOR and NOR were not calculated at $\mathrm{CD}$ due to the absent observation of gases.

During the haze episode, the organic material in the $\mathrm{PM}_{2.5}$ increased significantly besides sulfate and nitrate, especially evident at CD (Fig. 6). The higher loading of POM at CD than at the other three sites should be probably attributed to the coal combustion in this city (Zhao, et al., 2013). The $\mathrm{OC} / \mathrm{EC}$ ratio is widely used to identify the presence of secondary organic aerosols when the value exceeds 2.0 (Chow et al., 1994, 1996). In Table 1, it could be found that secondary organic aerosols existed in the $\mathrm{PM}_{2.5}$ on both haze and nonhaze days at TJ, BJ and SDZ, and increased on haze days with a higher $\mathrm{OC} / \mathrm{EC}$ ratio at $\mathrm{TJ}$ and $\mathrm{BJ}$ but changed slightly at SDZ. At the northern city CD, the OC / EC ratio was lower than 2.0 on non-haze days but significantly increased to 4.34 on haze days, which suggested that the secondary formation of organic aerosols had a greater regional impact during the haze episode. The analysis of chemical characteristics of aerosol indicated that the secondary formation of aerosol was one important mechanism in the haze formation.

\subsection{Accumulation and transport of pollutants in this episode}

As mentioned in Sect. 3.1, this haze episode was caused by a surface high-pressure system in the early phase and a lowpressure system in the later period. In Fig. 8, the temperature inversion could be found at about $800 \mathrm{hPa}$ on $16 \mathrm{Jan}-$ uary, which then strengthened and descended gradually over the following two days. The inversion lowered to the surface on 17 January with the strongest inversion occurring at around $900 \mathrm{hPa}$ in the night. The vertical wind presented in Fig. 9 was distinguished by two layers above and below $500 \mathrm{~m}$. The lower layer was mainly distributed under $400 \mathrm{~m}$ with low wind speed, and descending air in the whole layer. There was no obvious change in the wind pattern until the afternoon of 18 January. This corresponded to the dominated high-pressure system in this period. The descending motion in the lower troposphere forced the aerosol particles into a very shallow layer. With the measurement of lidar (Fig. 10), it could be found that the aerosol particles were mainly concentrated below $500 \mathrm{~m}$ during this episode. The maximum of aerosol loading was located around $200 \sim 400 \mathrm{~m}$. The 

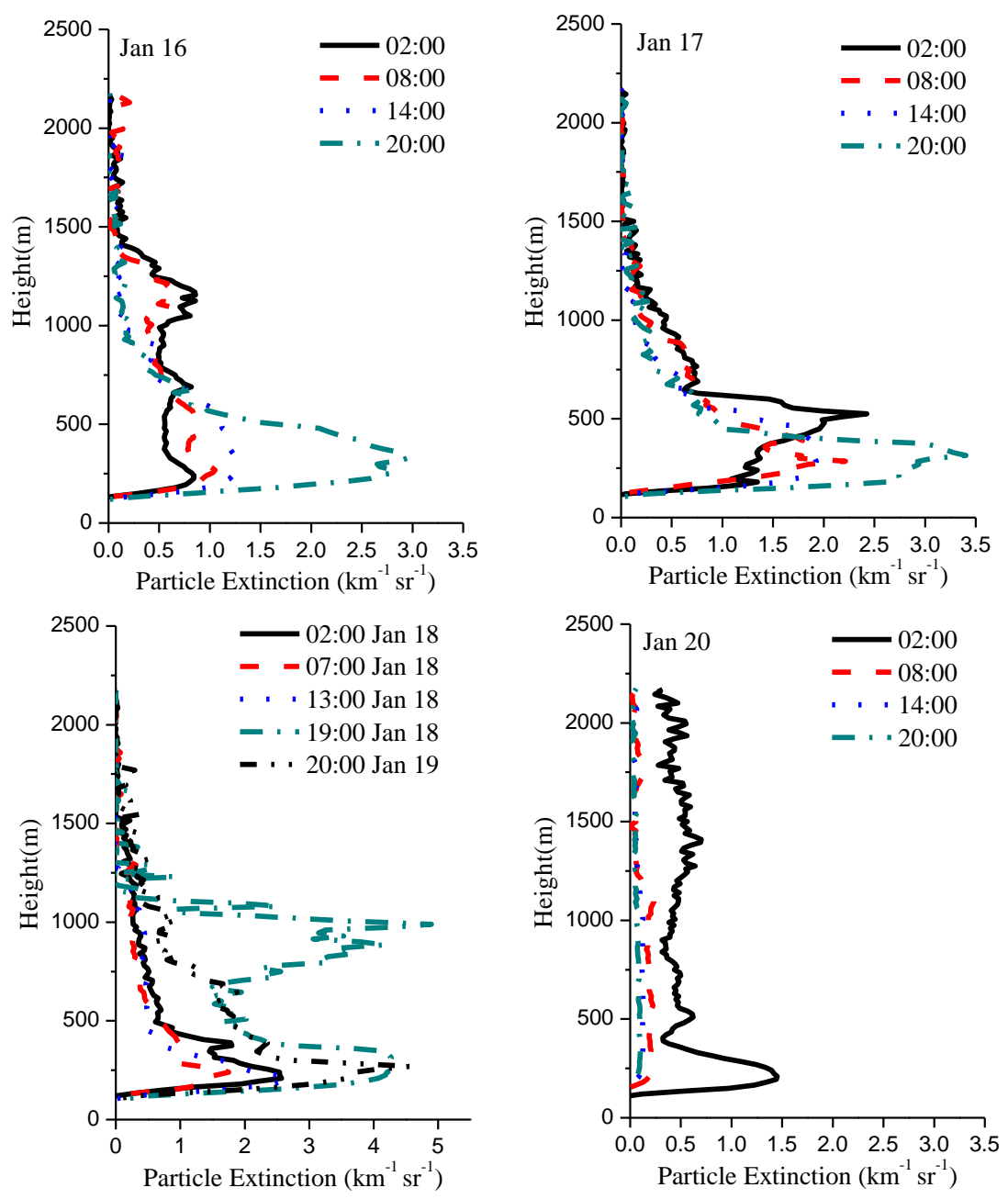

Fig. 10. Vertical profile of particle extinction at SDZ from 16 to 20 January.

similar vertical distribution of wind and aerosol indicated that the height of the PBL was about $400 \mathrm{~m}$. The shallow PBL severely limited pollutant diffusion in the vertical. The weak horizontal wind limited the horizontal dispersion of pollutants that produced very high concentrations in the urban area (such as BJ and $\mathrm{TJ}$ ) and relatively lower concentrations in the more suburban area (SDZ). However, the pollutant concentrations were still elevated above non-episode levels in the suburban area under the large-scale stagnation weather condition (Fig. 3d-f). The accumulation of pollution was the main factor in the haze formation on these three days. In the afternoon of 18 January, the controlling synoptic weather over Beijing and the surrounding area changed to a lowpressure system. The southwest wind appeared from the surface to $800 \mathrm{~m}$ and even stronger in the layer of $800 \sim 2000 \mathrm{~m}$, which transported the pollutants from the more southern regions toward the north. Correspondingly, a layer with high aerosol loading located about at 800 to $1000 \mathrm{~m}$ was observed at 19:00 (LT) on 18 January above the downwind area (Fig. 10). Accompanying the strong southwest wind, the en- hanced descent of air occurred in the whole vertical direction on 19 January, which carried part of pollutants to the ground. At the same time, the surface wind at SDZ turned from east-northeast to southwest in the afternoon of 18 January (Fig. 3a), and carried pollutants to this area that resulted in the highest aerosol loading in the lower aerosol layer on 19 January. The ground and high layer transport of pollutants resulted in the rapid increase of pollutants in the downwind area, but caused decrease of pollutants in urban area on 19 January (Fig. 3d-f). The regional transport of pollutants expanded the geographical extent of the haze. With the arrival of the Mongolian anticyclone, the northerly wind first appeared aloft and diluted pollutants in that layer of the atmosphere. The higher aerosol layer had disappeared at 20:00 (LT) on 19 January, while the surface layer still remained with high aerosol loading. On 20 January, the aerosol loading near the surface decreased significantly and finally the entire polluted volume was diluted and transported by the strong northerly wind that terminated this haze episode. 


\section{Summary and conclusion}

An intensive aerosol and trace gases campaign was carried out over the BTH region in the North China Plain from 14 to 23 January 2010. A regional haze episode, from 16 to 19 January, occurred during this period. With the analysis of the chemical and optical properties of aerosols and the meteorological conditions, the formation of this episode was investigated in this study.

The haze episode was caused by a surface high-pressure system during most of the time and by a low-pressure system in the later period. During this episode, the concentrations of $\mathrm{PM}_{2.5}$ and main trace gases increased significantly on a regional scale. The area with visibility lower than $10 \mathrm{~km}$ covered most regions of eastern China. The haze phenomenon recorded in daytime corresponding to the low visibility suggested that the aerosol loading was high enough in this episode to extinct the light. The increased $\sigma_{\mathrm{sp}}, \sigma_{\mathrm{ap}}$ and AOD further supported the important extinction effect of aerosol in the formation of this haze episode.

The secondary inorganic pollutants $\left(\mathrm{SO}_{4}^{2-}, \mathrm{NO}_{3}^{-}\right.$and $\mathrm{NH}_{4}^{+}$) and $\mathrm{OM}$ increased evidently during haze days and became dominant components of $\mathrm{PM}_{2.5}$. The concentration level of secondary pollutants was significantly higher in large cities than in the regional background area and city in the north area of the Hebei province, while the percentage was comparable at three sites in the North China Plain, and evidently higher than that at the CD site. The increase of secondary inorganic pollutants was observed simultaneously at four sites, especially in the plain area of BTH, which could be identified as a common characteristic of pollution haze in east China.

The sulfate and nitrate in $\mathrm{PM}_{2.5}$ was mainly formed through the heterogeneous reaction process at $\mathrm{BJ}$ and $\mathrm{TJ}$. At SDZ, the photochemical reaction, regional transport and heterogeneous reaction process probably together caused the increase of sulfate and nitrate. The secondary organic aerosols existed in the $\mathrm{PM}_{2.5}$ on both haze and non-haze days at TJ, $\mathrm{BJ}$ and SDZ, while they only existed on haze days at CD. The increase of secondary organic aerosols at the four sites suggested the greater regional impact of secondary formation process during the haze episode. The chemical characteristics of aerosols in $\mathrm{PM}_{2.5}$ indicated that the secondary formation of aerosol was one important mechanism in the formation of the haze episode.

The strong temperature inversion, weak surface wind speed and descending air motions in PBL caused pollutants to accumulate in a shallow layer and produced high pollutant concentrations within the source region. The accumulation of pollutants was one of the main factors in the haze formation. The enhanced southwest wind in the entire layer transported pollutants from the southern urban area to the downwind area in the later period, which expanded the geographical scope of the haze.
The unfavorable meteorological condition was the external cause of this regional haze. The secondary formation processes produced a large amount of aerosols that extinct light and resulted in the low visibility during this haze. However, the significant increase of pollutants at four sites especially in urban areas indicated that the anthropogenic emission on a regional scale was the basic reason of the regional haze. The control measures for ensuring air quality in megacity clusters should be taken on a regional scale.

Acknowledgements. This work was supported by the National Natural Science Foundation of China (41205121, 41105092), the Beijing Natural Science Foundation (8131003, 8132025, 8121002), the Research Funding of Institute of Urban Meteorology (IUMKY201209), and Special Grant in Atmospheric Sciences Field supported by CMA (GYHY200806027). The authors would like to thank the staff of the Shangdianzi and Chengde station for assisting the measurements. We also thank the editor for his helpful comments and suggestions on the manuscript and for polishing the English writing.

Edited by: D. Covert

\section{References}

Bergin, M., Cass, G. R., Xu, J., Fang, F., Zeng, L. M., Yu T., Salmon, L. G., Kiang, C. S., Tang, X. Y., Zhang, Y. H., and Chameides, W. L.: Aerosol radiative, physical, and chemical properties in Beijing during June 1999, J. Geophys. Res., 106, 17969-17980, 2001.

Bond, T. C. and Bergstrom R. W.: Light Absorption by Carbonaceous Particles: An Investigative Review, Aerosol Sci. Technol., 40, 27-47, 2006.

Calvert, J., Lazrus, A., Kok, G., Heikes, B., Walega, J., Lind, J., and Cantrell, C.: Chemical mechanisms of acid generation in the troposphere, Nature 317, 27-35, doi:10.1038/317027a0, 1985.

Chow, J. C., Watson, J. G., Crow, D., Lowenthal, D. H., and Merrifield, T.: Comparison of IMPROVE and NIOSH carbon measurements, Aerosol Sci. Technol., 34, 23-34, 2001.

Chow, J. C., Watson, J. G., Pritchett, L. C., Pierson, W. R., Frazier, C. A., and Purcell, R. G.: The DRI thermal/optical reflectance carbon analysis system: Description, evaluation and application in U.S. air quality studies, Atmos. Environ., 27A, 1185$1201,1993$.

Chow, J., Waston, J., Chen, L., Chang, M., Robinson, N., Trimble, D., and Kohl, S.: The IMPROVE_A temperature protocol for thermal/optical carbon analysis: maintaining consistency with a long-term database, J. Air Waste Manage., 57, 1014-1023, 2007.

Chow, J. C., Watson, J. G., Fujita, E. M., Lu, Z., and Lawson, D. R.: Temporal and spatial variations of $\mathrm{PM}_{2.5}$ and $\mathrm{PM}_{10}$ aerosol in the southern California air quality study, Atmos. Environ., 28, 3773-3785, 1994.

Chow, J. C., Watson, J. G., Lu, Z., Lowenthal, D. H., Frazier, C. A., Solomom, P. A., Thuiller, R. H., and Magliano, K.: Descriptive analysis of $\mathrm{PM}_{2.5}$ and $\mathrm{PM}_{10}$ at regionally representative locations during SJVAQS/AUSPEX, Atmos. Environ., 30, 20792112, 1996. 
Fernald, F. G.: Analysis of Atmospheric Lidar Observations - Some Comments, Appl. Opt., 23, 652-653, 1984.

Hua, W., Chen, Z. M., Jie, C. Y., Kondo, Y., Hofzumahaus, A., Takegawa, N., Chang, C. C., Lu, K. D., Miyazaki, Y., Kita, K., Wang, H. L., Zhang, Y. H., and Hu, M.: Atmospheric hydrogen peroxide and organic hydroperoxides during PRIDE-PRD'06, China: their concentration, formation mechanism and contribution to secondary aerosols, Atmos. Chem. Phys., 8, 6755-6773, doi:10.5194/acp-8-6755-2008, 2008.

Huang, K. Zhuang, G., Lin, Y., Fu, J. S., Wang, Q., Liu, T., Zhang, R., Jiang, Y., Deng, C., Fu, Q., Hsu, N. C., Cao , B: Typical types and formation mechanisms of haze in an Eastern Asia megacity, Shanghai, Atmos. Chem. Phys., 12, 105-124, 2012, http://www.atmos-chem-phys.net/12/105/2012/.

Hueglin, C., Gehrig, R., Baltensperger, U., Gysel, M., Monnd, C., and Vonmonta, H.: Chemical characteristics of $\mathrm{PM}_{2.5}, \mathrm{PM}_{10}$ and coarse particles at urban, near-city and rural sites in Switzerland, Atmos. Environ., 39, 637-651, 2005.

Husar, R. B. and Wilson, W. E.: Haze and sulfur emission trends in the eastern United States, Environ. Sci. Technol., 27, 12-16, 1993.

Kang, H., Zhu, B., Su, J., Wang, H., Zhang, Q., and Wang, F.: Analysis of a long-lasting haze episode in Nanjing, China, Atmos. Res., 120-121, 78-87, 2013.

Klett J. D.: Lidar inversions with variable backscatter/extinction values, Appl. Opt., 24, 1638-1643, 1985.

Klett J. D.: Stable analytical inversion solution for processing Lidar returns, Appl. Opt., 20, 211-220, 1981.

Li, W. J., Shao, L. Y., and Buseck, P. R.: Haze types in Beijing and the influence of agricultural biomass burning, Atmos. Chem. Phys., 10, 8119-8130, doi:10.5194/acp-10-8119-2010, 2010.

Li, W. J., Zhou, S., Wang, X., Xu, Z., Yuan, C., Yu, Y., Zhang, Q., and Wang, W.: Integrated evaluation of aerosols from regional brown hazes over northern China in winter: Concentrations, sources, transformation, and mixing states, J. Geophys. Res., 116, D09301, doi:10.1029/2010JD015099, 2011.

Lin, W., Xu, X., Zhang, X., and Tang, J.: Contributions of pollutants from North China Plain to surface ozone at the Shangdianzi GAW Station, Atmos. Chem. Phys., 8, 5889-5898, doi:10.5194/acp-8-5889-2008, 2008.

Ma, N., Zhao, C. S., Nowak, A., Müller, T., Pfeifer, S., Cheng, Y. F., Deng, Z.Z., Liu, P. F., Xu, W. Y., Ran, L., Yan, P., Göbel, T., Hallbauer, E., Mildenberger, K., Henning, S., Yu, J., Chen, L. L., Zhou, X. J., Stratmann, F., and Wiedensohler, A.: Aerosol optical properties in the North China Plain during HaChi campaign: an in-situ optical closure study, Atmos. Chem. Phys., 11, 59595973, doi:10.5194/acp-11-5959-2011, 2011.

Molnár, A. Mészáros, E., Imre, K., and Rüll, A.: Trends in visibility over Hungary between 1996 and 2002, Atmos. Environ., 42, 2621-2629, 2008.

Parrish, D. D. and Zhu, T.: Clean Air for Megacities, Science, 326, 674-675, 2009.

Poppe, D., Wallasch, M., and Zimmermann, J.: The dependence of the concentration of $\mathrm{OH}$ on its precursors under moderately polluted conditions: a model study, J. Atmos. Chem., 16, 61-78, 1993.

Schichte, B. A., Husar, R. B., Falke, S. R., and Wilson, W. E.: Haze trends over the United States, 1980-1995, Atmos. Environ., 35, 5205-5210, 2001.
Seinfeld, J. H.: Atmospheric Chemistry and Physics of Air Pollution; Wiley: New York, 1986.

Sun, Y. L., Zhuang, G. S., Wang, Y., Han, L. H., Guo, J. H., Dan, M., Zhang, W. J., Wang, Z. F., and Hao, Z. P.: The air-borne particulate pollution in Beijing-concentration, composition, distribution and sources, Atmos. Environ., 38, 5991-6004, 2004.

Sun, Y., Zhuang, G., Tang, A., Wang, Y., and An, Z.: Chemical characteristics of $\mathrm{PM}_{2.5}$ and $\mathrm{PM}_{10}$ in haze-fog episodes in Beijing, Environ. Sci. Technol. 40, 3148-3155, 2006.

Sun, Y. L., Wang, Z. F., Fu, P. Q., Yang, T., Jiang, Q., Dong, H. B., Li, J., and Jia, J. J.: Aerosol composition, sources and processes during wintertime in Beijing, China, Atmos. Chem. Phys., 13, 4577-4592, doi:10.5194/acp-13-4577-2013, 2013.

Tan, J. H., Duan, J.C., Chen, D. H., Wang, X. H., Guo, S. J., Bi, X. H., Sheng, G. Y., He, K. B., and Fu, J. M.: Chemical characteristics of haze during summer and winter in Guangzhou, Atmos. Res., 94, 238-245, 2009.

Taylor, S. R. and Mclennan, S. M.: The Continental Crust: Its Composition and Evolution. Blackwells, Oxford, England, 1985.

Wang, X., Wang, W., Yang, L., Gao, X., Nie, W., Yu, Y., Xu, P., Zhou, Y., and Wang, Z.: The secondary formation of inorganic aerosols in the droplet mode through heterogeneous aqueous reactions under haze conditions, Atmos. Environ., 63, 68-76, 2012.

Wang, Y., Zhuang, G. S., Sun, Y. L., and Zheng, A.: The variation of characteristics and formation mechanisms of aerosols in dust, haze, and clear days in Beijing, Atmos. Environ., 40, 6579-6591, 2006..

Xu, W. Y., Zhao, C. S., Ran, L., Deng, Z. Z., Liu, P. F., Ma, N., Lin, W. L., Xu, X. B., Yan, P., He, X., Yu, J., Liang, W. D., and Chen, L. L.: Characteristics of pollutants and their correlation to meteorological conditions at a suburban site in the North China Plain, Atmos. Chem. Phys., 11, 4353-4369, doi:10.5194/acp-114353-2011, 2011.

Zhang, X. Y., Gong, S. L., Shen, Z. X., Mei, F. M., Xi, X. X., Liu, L. C., Zhou, Z. J., Wang, D., Wang, Y. Q., and Cheng, Y.: Characterization of soil dust aerosol in China and its transport and distribution during 2001 ACE-Asia:1. Network observations, J. Geophys. Res., 108, 4261, doi:10.1029/2002JD002632, 2003.

Zhao, P. S., Dong, F., He, D., Zhao, X. J., Zhang, X. L., Zhang, W. Z., Yao, Q., and Liu, H. Y.: Characteristics of concentrations and chemical compositions for $\mathrm{PM}_{2.5}$ in the region of Beijing, Tianjin, and Hebei, China, Atmos. Chem. Phys., 13, 4631-4644, doi:10.5194/acp-13-4631-2013, 2013.

Zhao, P. S., Zhang, X. L., Xu, X. F., and Zhao, X. J.: Long-term visibility trends and characteristics in the region of Beijing, Tianjin, and Hebei, China, Atmos. Res., 101, 711-718, $2011 \mathrm{a}$.

Zhao, X. J., Zhang, X. L., Pu, W. W., Meng, W., Xu, X. F.: Scattering properties of the atmospheric aerosol in Beijing, China, Atmos. Res., 101, 799-808, 2011b.

Zhao, P. S., Zhang, X. L., and Xu, X. F.: Comparison between two methods of distinguishing haze days with daily mean and 14 o'clock meteorological data, Acta Scientiae Circumstantiae, 31, 704-708, 2011c (in Chinese).

Zhao, X. J., Zhang, X. L., Xu, X., F. Xu, J., Meng, M., and Pu, W. W.: Seasonal and diurnal variations of ambient $\mathrm{PM}_{2.5}$ concentration in urban and rural environments in Beijing, Atmos. Environ., 43, 2893-2900, 2009. 